\title{
Magnetic Resonance Imaging of Perianal Fistulas in Clinically Symptomatic Patients and the Correlation Among Plain, Contrast, and Post Jelly MRI Fistulography
}

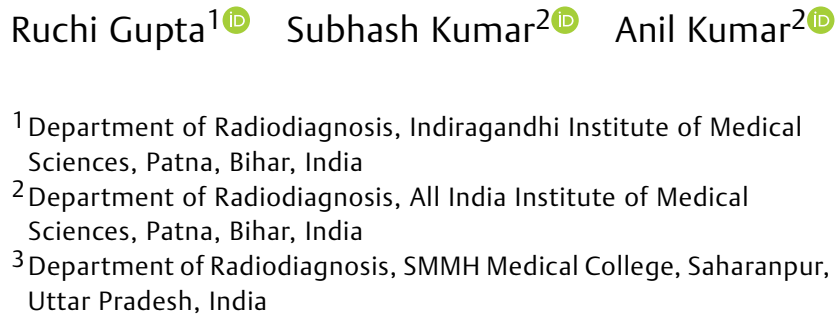

\author{
Richa Tiwari ${ }^{3}$ Neetu Sinha1잉
}

\begin{abstract}
Keywords

- fistulography

- MRI

- jelly

- contrast

- perianal

- St. James classification

Objectives To evaluate different types of perianal fistulas and their complications on magnetic resonance imaging (MRI) and to compare plain, contrast, and jelly magnetic resonance fistulography findings.

Materials and Methods This prospective study was performed in 30 patients who presented with perianal pus discharge or external fistulous opening. Magnetic resonance imaging of the perianal region before and after giving intravenous contrast and after injecting jelly through a percutaneous opening was performed on a 3T scanner and the results were correlated.

Results The mean age of the patients was $40.13 \pm 13.88$ years (range $19-75$ years). The male to female ratio was 14:1. The most common type of fistula was St. James classification type I, which was seen in 13 patients (43\%), followed by type IV in $30 \%$, type III in $16 \%$, type II in $6.66 \%$, and type V in $3.33 \%$ of the patients. Using agreement analysis, we compared the number of primary and secondary tracts, internal openings, and horseshoe tracts and found a significant agreement between plain and post jelly MRI fistulography (kappa statistic close to 1). When comparing plain and contrast MRI, there was significant agreement in the primary and secondary tracts, while statistically insignificant results were obtained $(p>0.05)$ for the horseshoe tract and internal openings. Contrast injection was helpful in 7 subjects (23.3\%) as peripheral enhancement of abscesses were better delineated.

Conclusion Magnetic resonance imaging is the one stop diagnostic modality for perianal fistulas. Acquisition of axial (Ax) T2, axial T2 FS, coronal T2 and coronal T2 FS sequences without administering intravenous contrast or jelly is usually sufficient for the diagnosis of fistulas and their complications.
\end{abstract}

received

August 29, 2020 accepted after revision January 15, 2021 published online July 19, 2021
DOI https://doi.org/ 10.1055/s-0041-1730260. ISSN 2237-9363.

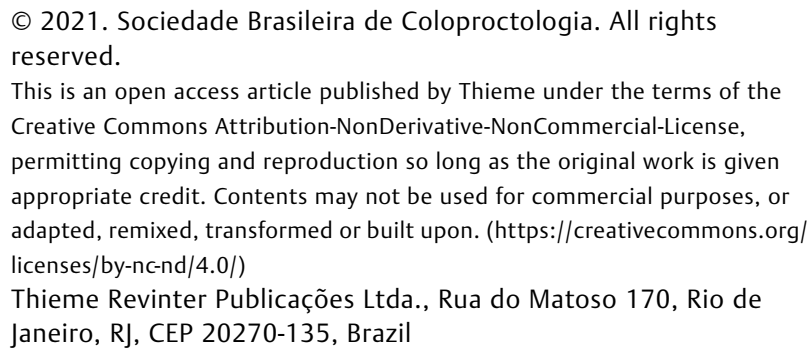

(c) 2021. Sociedade Brasileira de Coloproctologia. All rights reserved.

This is an open access article published by Thieme under the terms of the Creative Commons Attribution-NonDerivative-NonCommercial-License, permitting copying and reproduction so long as the original work is given appropriate credit. Contents may not be used for commercial purposes, or adapted, remixed, transformed or built upon. (https://creativecommons.org/ licenses/by-nc-nd/4.0/)

Thieme Revinter Publicações Ltda., Rua do Matoso 170, Rio de Janeiro, RJ, CEP 20270-135, Brazil 


\section{Introduction}

Perianal fistula is a disease that originates from anal gland infections. Preoperative assessment of the course and type of fistula and the presence of associated findings is a must for the successful surgical outcome. Recurrence is also a major concern in this disease; hence, knowing the extensions of disease helps in surgical elimination of all sources of infection and ultimately decreases the percentage of recurrent disease. ${ }^{1}$ Magnetic resonance imaging (MRI) is the imaging modality of choice for diagnosing the type and complications associated with the fistula. ${ }^{2}$ The research questions addressed in the study were: What are the different types of perianal fistulas, their complications in our study group, and the difference between plain, jelly, and contrast (cont) MRI studies? The study was designed so that the final protocol could be established and followed in routine working practice.

\section{Materials and Methods}

This prospective study included 30 patients above the age of 18 years who presented with complaints of perianal pus discharge or any external fistulous opening to the surgical outpatient department from May 2017 to June 2018. The exclusion criteria were postsurgical cases, proven tuberculosis, proven inflammatory bowel disease, malignancy, and pregnancy, and the exclusion criteria for performing MRI were claustrophobia, pacemaker, cochlear implant, other metallic implants, and metallic foreign body. The procedure was explained to all the patients, and written consent was taken in their language. For MRI, a vitamin E capsule was used as a marker. Magnetic resonance imaging was done on a Discovery 750w 3T scanner (GE Healthcare, Milwaukee, WI, USA) using a 24-channel body coil. The following sequences were taken: localizer, T1 turbo spin echo (TSE) axial, T2 TSE axial, T2 TSE coronal (cor), T2 Fat Sat (FS) Axial, and Coronal T2 FS sequences (Plain MRI fistulography). Aqueous ultrasound jelly was injected through percutanous perianal external opening by inner plastic sheath of 20G intravenous cannula. After percutaneous instillation of aqeuous ultrasound jelly, 3D CUBE T2 FS sequence was aquired (post Jelly MRI fistulography). Then, contrast study was performed using a $287 \mathrm{mg} / \mathrm{ml}$ Omniscan Gadodiamide Intravenous injection (GE Heathcare). The dose was $0.1 \mathrm{mmol} / \mathrm{kg}$ body weight in all patients. Post contrast T1 FS Axial, Coronal and Sagittal sequences were acquired (Contrast MRI fistulography) - Table 1.

\section{Results}

The mean age of patients in the present study was $40.13 \pm 13.88$ years (range 19-75 years). Twenty-eight patients were male and 2 were female ( $\mathrm{M} / \mathrm{F}$ ratio was $14: 1)$. The anus was considered as a clock and both external and internal openings of the fistula were seen on axial images and reported according to this clock. In lithotomy position, 12 o'clock was anterior midline, 6 o'clock posterior midline, 3 o'clock was to the left and 9 o'clock to the right. The most

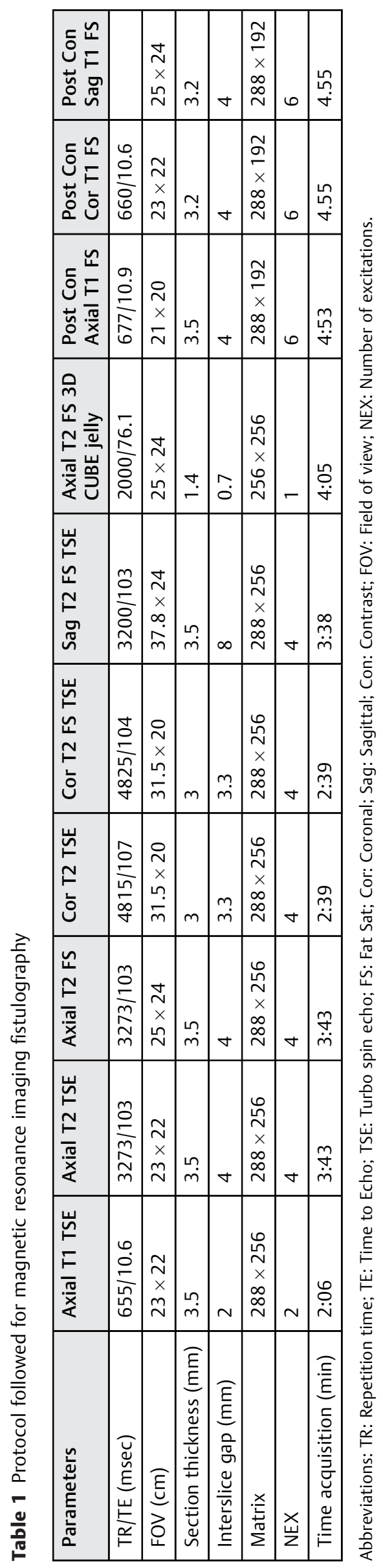




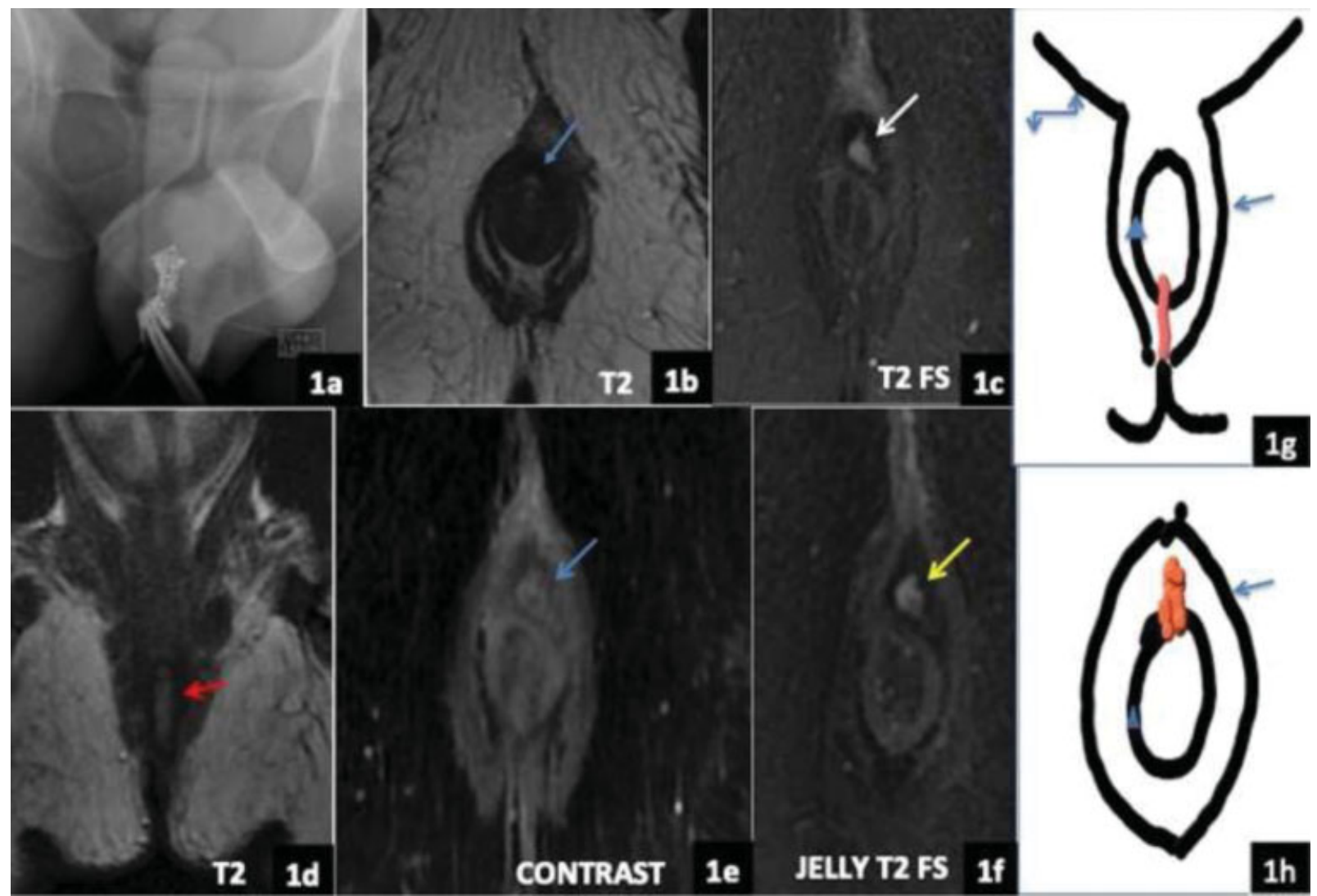

Fig. 1 INTERSPHINCTERIC FISTULA TYPE I (A) X-ray fistulography showing the contrast filled tract (prone position). (B) Axial T2. (C) Axial T2FS. (D) Coronal T2. (E) Postcontrast axial. (F) Axial T2FS jelly images showing the intersphincteric tract with internal and external openings at the 12 o'clock position. Line diagrams (1 $\mathbf{g})$ Coronal and $(\mathbf{~ h})$. Axial images showing the external sphincter (arrow), internal sphincter (triangle), levator ani muscle (curved arrow), and intersphincteric tract (red in color).

common type of fistula was St. James classification type I intersphincteric fistula, which was seen in 13 patients (43\%) [-Figs. 1, 2]. The incidence of the rest was as follows: type II in $2(6.66 \%)$ [-Fig. 3], type III in 5 (16\%) (-Figs. 4, 5), type IV in 9 patients (30\%) (-Figs. 6, 7), and type $\mathrm{V}$ in 1 patient (3.33\%) (-Fig. 8). Finally, the Goodsall rule was followed in 26 subjects (86.6\%). In 19 patients (73\%), the external opening was posterior to the transverse anal line and the internal opening was seen at 6 o'clock; 2 patients had both external and internal openings at 12 o'clock; 4 patients had an external opening present anteriorly, but the tract coursed posteriorly with internal opening at 6 o'clock (15.3\%), and one patient had an external opening at 3 o'clock and an internal opening at 2 o'clock (radial tract). In 10 out of 13 patients with type-I fistulas, both internal and external openings were seen at the 6 o'clock position, while in 2 cases, they were at 12 o'clock.
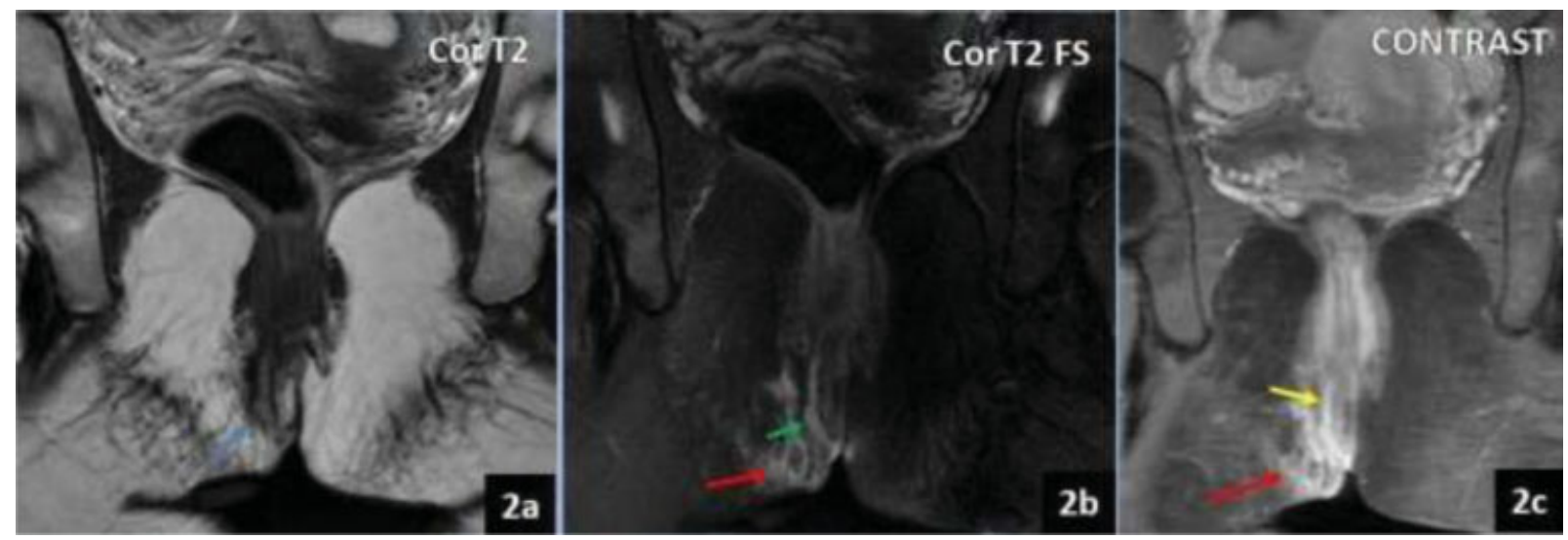

Fig. 2 INTERSPHINCTERIC FISTULA TYPE I. (A) Coronal T2 TSE image showing linear hyperintense tract (blue). (B) Coronal T2 FS image showing the tract (green). (C) Coronal postcontrast image showing enhancing tract (yellow). Surrounding inflammatory changes seen in both $\mathrm{T} 2 \mathrm{FS}$ and postcontrast image (red). 

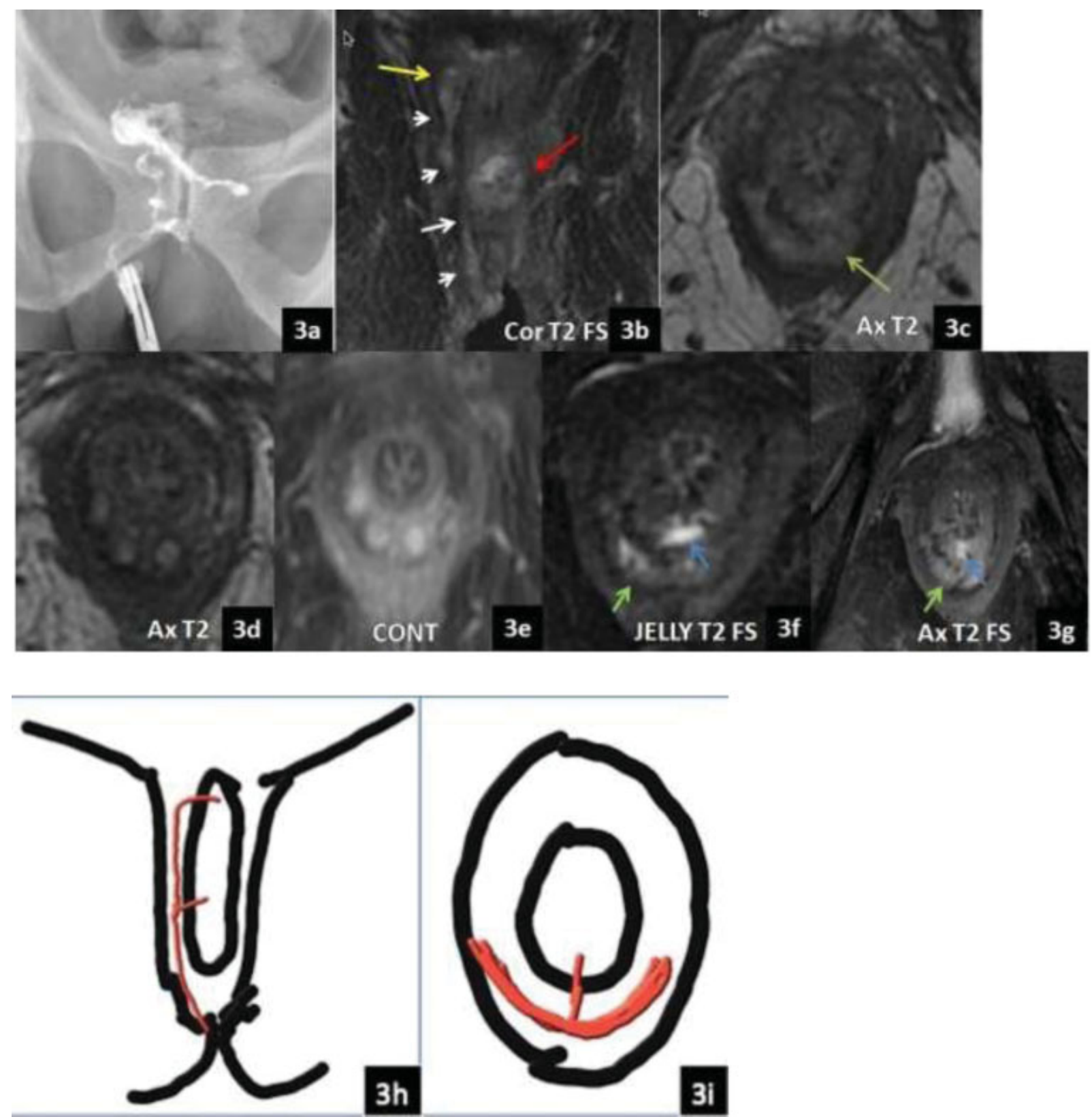

Fig. 3 INTERSPHINCTERIC FISTULA TYPE II. (A) X-ray fistulography showing the main tract opacifying the ano-rectum and giving secondary tract in mid-way ending blindly. (B) Coronal T2FS showing the tract, internal opening (yellow) at 9 o'clock, and horseshoe secondary tract (red). (C) Axial T2WI showing horseshoe secondary tract in the mid portion of the main tract crossing midline (green). (D) Axial T2. (E) Postcontrast axial images show three secondary tracts arising from horseshoe tract end blindly. (F) Jelly fistulography and (G) axial T2 FS image showing horseshoe tract (green arrow) with internal opening at 6 o'clock (blue arrow). Hence, there were two internal openings (9 and 6 o'clock).

Line diagrams, (H) Coronal and (I) Axial images showing the tract in red color with two internal openings and horseshoe tract in intersphincteric plane.

Out of 30 subjects, 23 had internal openings at 6 o'clock (76\%). In one patient, the internal opening was not appreciated in any of the sequences. The number of primary and secondary tracts, horseshoe tracts, and internal openings were evaluated separately in plain, jelly, and contrast MRI. Overall, there were 33 primary, 9 secondary, 5 horseshoe tracts, and 31 internal openings in plain MRIs. In post Jelly MRI fistulography (3D CUBE T2 FS Axial sequence after percutaneous instillation of aqueous jelly through external opening), there were 32 primary tracts, 9 secondary tracts, 5 horseshoe tracts, and 30 internal openings, while in contrast MRI, 33 primary tract, 5 secondary tract, 5 horseshoe tract, and 27 internal openings were observed. Peripheral enhancement of the tract was seen in 7 patients, suggestive of abscess, while enhancing granulation tissue was seen at the external opening in 1 patient. Overall, contrast was helpful in 12 subjects (40\%) as the enhancement of perifistulous inflammatory changes and the abscesses were better delineated. Statistical analysis was performed using the IBM SPSS for Windows, Version 22.0 software (IBM Corp., Armonk, NY, USA). The agreement analysis between plain and jelly, plain and contrast, and contrast and jelly MRI fistulography was done to determine the agreement between two 


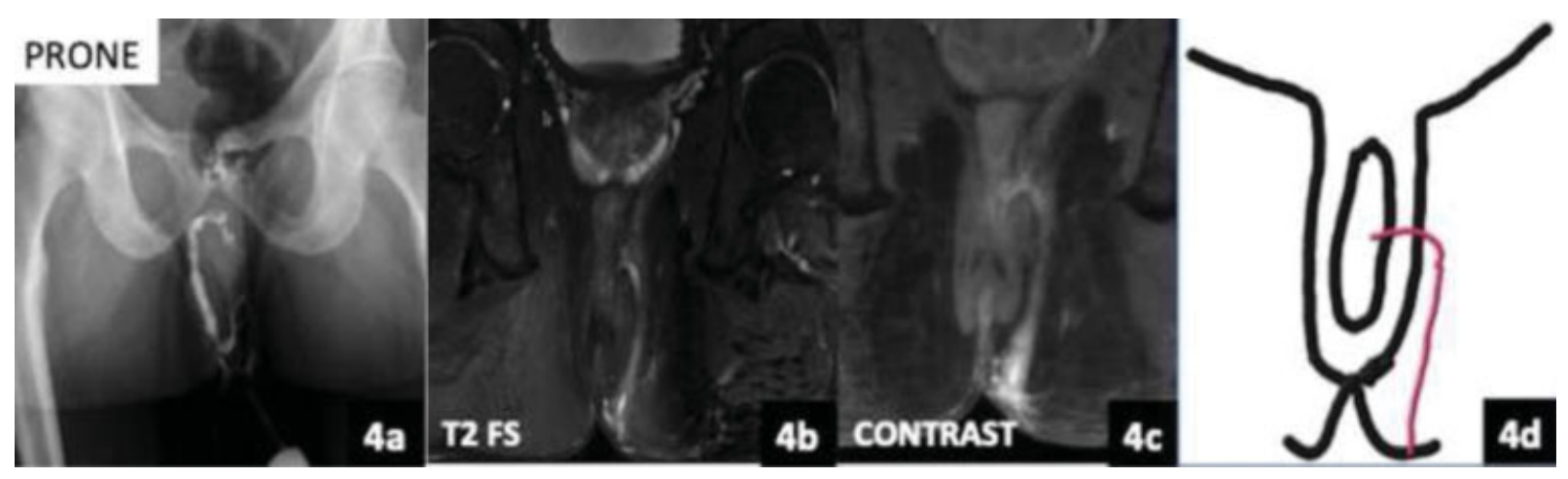

Fig. 4 TRANSPHINCTERIC FISTULA TYPE III. (A) X-ray fistulography showing long fistulous tract joining the ano-rectum with opacification of the latter. (B) Coronal T2 FS image showing the fistulous tract taking transphincteric course with internal opening at 3 o'clock. (C) Postcontrast coronal fat sat image showing the enhancing tract. No secondary tracts or abscess. Line diagram (D) Coronal image shows the transphincteric tract.

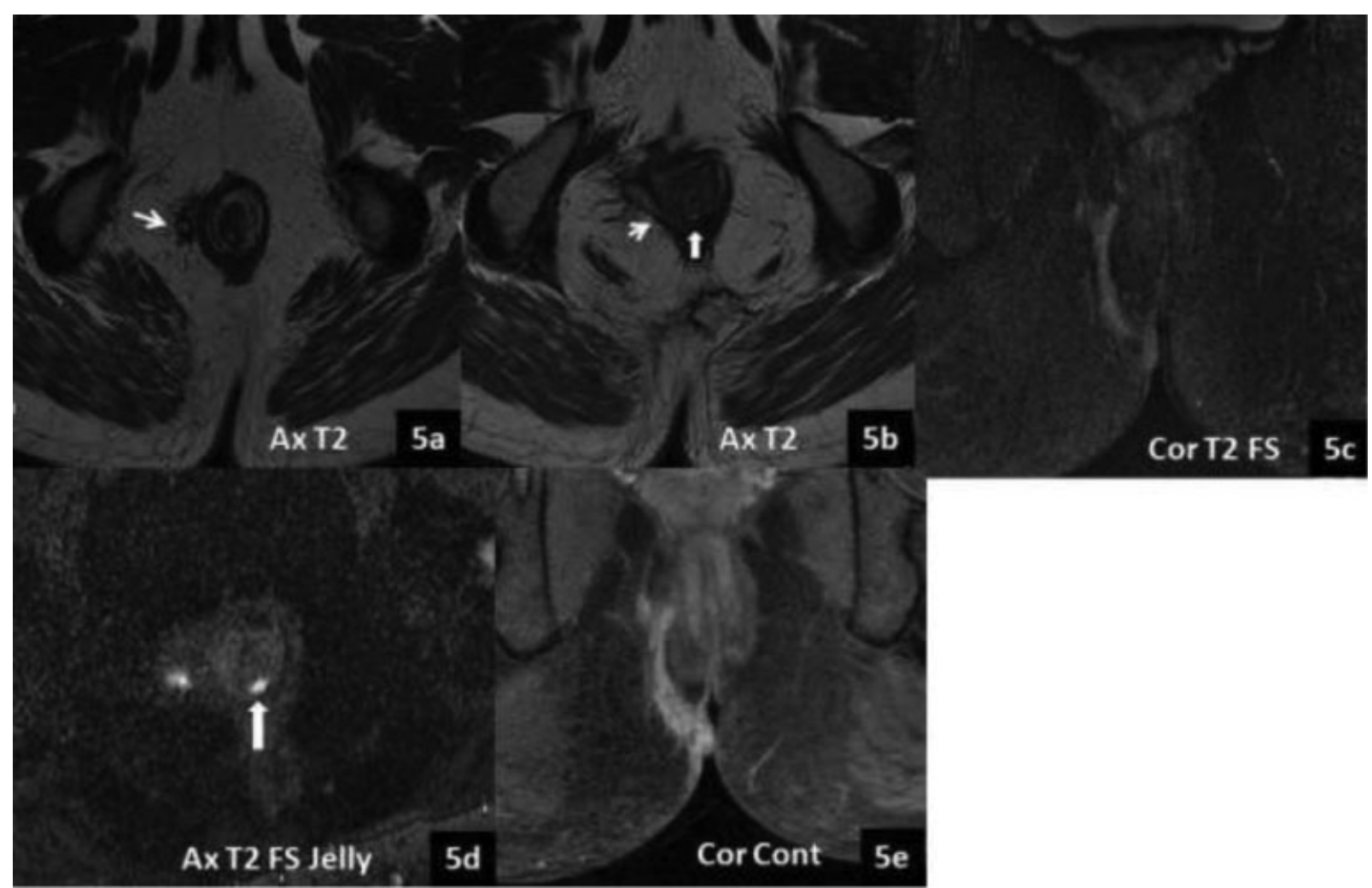

Fig. 5 TYPE III TRANSPHINCTERC FISTULA. Axial T2 image (A, B) and COR T2FS image (C) showing hyperintense tract in the right ischioanal fat, piercing the external sphincteric nearly at 7 to 8 o'clock (white arrows) and internal sphincter at 6 o'clock (block arrow) (B). However, internal opening is not very conspicuous (B). Cube axial T2FS jelly image (D) shows internal opening is better visualized. COR T1FS post contrast image (E) shows enhancing active tract.

modalities, and the kappa statistic and p-value were calculated. ( - Tables 2, 3, 4) Between plain and jelly MRI fistulography, there was significant agreement in secondary tract visualization, while for primary tract, horseshoe tract and internal openings, kappa statistic was close to +1 (strong agreement). Similarly, between plain and contrast MRI, there was significant agreement in secondary tract visualization. For primary and horseshoe tracts, kappa statistic was close to +1 , while in internal openings, the agreement was not significant $(p>0.05)$. For jelly MRI fistulography and contrast MRI, there was significant agreement in secondary and horseshoe tracts visualization. For primary tract, kappa statistic was close to +1 while in internal openings, the agreement was not significant $(p>0.05)$.

Plain MRI findings were sufficient to make the diagnosis in all 30 subjects. Jelly insertion could not be done in one patient because the tract was inactive and no pus discharge was present. The advantage of 3D CUBE T2 FS sequence acquired after jelly injection was that it helped in obtaining reformatted images, determining the accurate length of the primary 


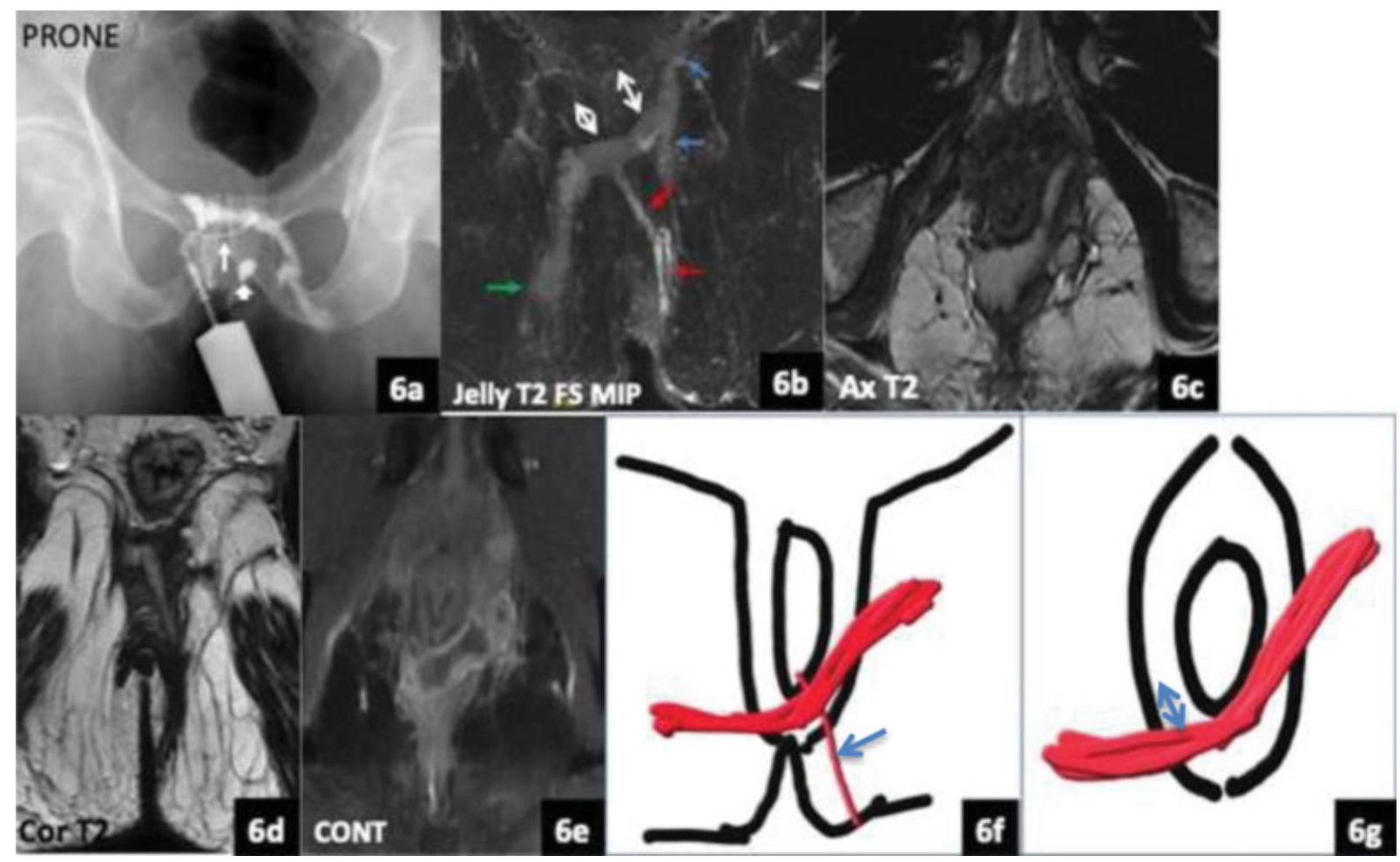

Fig. 6 TRANSPHINCTERIC FISTULA TYPE IV. (A) X-ray fistulography showing thin tract (arrow) commencing into thick horseshoe tract crossing to opposite side. Contrast-soaked cotton swab at the anal opening (block arrow). (B) Jelly coronal T2 FS MIP image shows long transphincteric fistula (red), thick horseshoe tract (double head arrows) in intersphincteric plane piercing the external sphincter on both sides to enter the ischioanal fossa. On the right side, it ends blindly (green), and on left side, give two secondary tracts ending blindly (blue). (C) Axial T2 image showing hyperintense horseshoe tract. (D) Coronal T2 image showing transphincteric tract. (E) Postcontrast axial image showing peripheral enhancement of the horseshoe tract s/o abscess. Line diagrams (F) Coronal and (G) Axial images showinh the thin transphincteric tract (arrow) and thick horseshoe tract (double headed arrow).

and secondary tracts, and in obtaining maximum intensity projection (MIP) images with better delineation of the tract.

\section{Discussion}

The anal region is surrounded by an internal sphincter composed of innermost mucosa, inner circular muscle (internal sphincter), and outer longitudinal muscle layer. The external somatic part is voluntary and composed of various components of external sphincter and puborectalis muscles; hence, the anus looks like two tubes, one within the other. ${ }^{3}$ Anal skin extends into the anal canal for $\sim 2 \mathrm{~cm}$ where the junction of squamous and columnar epithelium forms the dentate line. At this junction, lie the anal glands, which drain into the anal sinuses. The anal glands lie within the intersphincteric space (between the internal and external sphincters, longitudinal muscle is the component of the space) or the internal sphincter. Once an abscess forms within the glands, if untreated, the infection may track through the longitudinal muscle (intersphincteric space). There are irregular fibrous septae within the somatic muscles which may become a possible course of fistulous tract. ${ }^{3,4}$ Parks et al. had proposed that infection in the anal glands can lead to fistula in ano formation in over $90 \%$ of cases. Cystic dilation of these glands is the precursor of infection. ${ }^{3}$

In 1976, Parks et al. had classified fistula in ano into four main groups; Intersphincteric (the most common of all), trans- sphincteric (the tract passes from the intersphincteric plane through the external sphincter complex into the ischiorectal fossa), suprasphincteric (the track passes through the intersphincteric plane upwards, through the levator muscle into the ischiorectal fossa, and then onto the perineal skin), and extrasphincteric (the least common of all - the track passes from the perineal skin into the ischorectal fat and levator ani muscle and opens into the rectum). ${ }^{5}$ This anatomic classification is particularly useful for the operating surgeons.

With the advent of MRI, a new classification system was proposed by the St. James University Hospital, considering the anus as a clock seen on axial images, with the exact clock position used by the surgeons for describing the site and direction of tracts in lithotomy position. ${ }^{1}$ The Five grades were proposed based on axial and coronal sequences; grade1 - simple intersphincteric fistula, grade 2 - intersphincteric fistula with intersphincteric abscess or secondary fistulous track, grade 3 - trans-sphincteric fistula, grade 4 - transsphincteric fistula with abscess or secondary track within the ischioanal or ischiorectal fossa, and grade 5 - supralevator and translevator disease. ${ }^{1,6}$ We used this classification system in our study and compared the findings of plain MRI with postcontrast and jelly MRI fistulography.

Al Khawaria et al., in 2005, studied the role of MRI in preoperative assessment of fistula in ano and found that 21 out of 26 patients had active fistula and MRI findings were in 


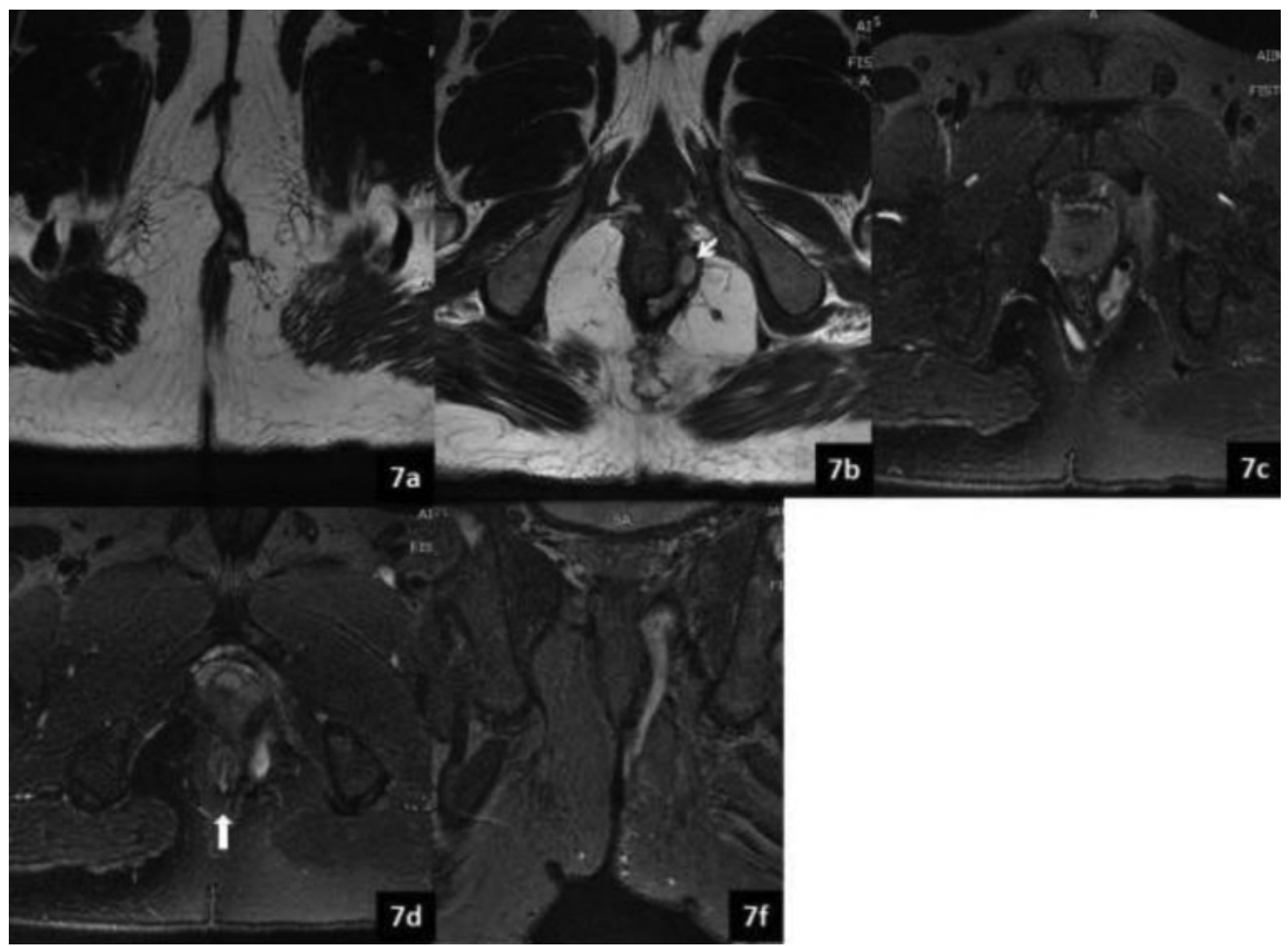

Fig. 7 TRANSSPHINCTERIC FISTULA TYPE IV. (A) Axial T2 image showing external opening at 12 o'clock, (B) piercing external sphincter at $\sim 2$ to 3 o'clock (white arrow) and becoming horseshoe tract in the intersphincteric plane. (C) Ax T2FS image showing the tract ascending upwards on the left side in the intersphincteric plane and fluid collection and air focus within s/o abscess. (D) Ax T2 FS image showing internal opening at 6 o'clock position (block arrow). (E) Coronal T2 FS image showing transphincteric fistula and an abscess deep in the left levator ani muscle. The plain study is sufficient to make the diagnosis.

accordance with surgical findings in 15 out of 16 cases. $^{7}$ Khera et al. studied 44 fistulae in 35 patients on $1.5 T$ MRI, and their study showed that $60 \%$ of fistulas were intersphincteric, 33\% transphincteric, $7 \%$ extrasphincteric, $61 \%$ were simple, and the rest showed complications. The authors concluded that combining enhanced T1-weighted (T1W) image with fat-suppressed T2-weighted (T2W) image provides most of the details necessary for accurate evaluation of perianal fistulae. ${ }^{8}$ Waniczek et al. studied the efficacy of MRI fistulography in 14 patients on 1.5T MRI and found that the radiological findings on $\mathrm{T} 2 \mathrm{~W}, \mathrm{~T} 2 \mathrm{FS}$ and postcontrast sequences were concordant with the surgical findings in 13 patients. ${ }^{9}$ In a study done by Daabis et al., 12 out of 24 patients had internal opening at the 6 o'clock position, and type-I fistula was the most common (37.5\%). ${ }^{10}$ In our study, 23 subjects had internal opening at 6 o'clock posteriorly (76\%), and type-I fistula was most common; hence, our findings are comparable to the ones in those studies.

In an evaluation of 411 fistulas in 367 patients, there was strong agreement between MRI and surgical findings. Combined T2W TSE and postcontrast fat sat T1W TSE sequences had high sensitivity (96.6\% and $98.4 \%$, respectively) and specificity (92.6\% and $81.5 \%$, respectively) for depicting internal openings and secondary tracts, and postcontrast T1 FS TSE sequence was $100 \%$ accurate in delineating abscesses. ${ }^{11}$ In our study, we compared plain MRI study including axial T1W, axial and coronal oblique T2 W and T2 FS images with postcontrast axial, coronal, and sagittal T1 FS TSE images. We found that T2 and T2FS images were sufficient to make the diagnosis of fistulas as well as their complications in all 30 patients (100\%). Sagittal images were not helpful in making the diagnosis in any of the cases. The contrast study helped in better delineation of abscesses and inflammatory changes in 12 patients (40\%). In our study, comparing plain and contrast MRIs, there was strong agreement in the delineation of primary, secondary, and horseshoe tracts, while in internal openings, the agreement was not significant $(p>0.05)$.

In a study done by Joshi et al. on 3T MRI in 25 patients, axial T1 TSE, T2 TSE, and T2 spectral Attenuated Inversion Recovery (SPAIR), and T2 SPAIR sagittal and coronal images were acquired and found that these sequences were sufficient to make the diagnosis of different perianal fistulas and their complications in all 25 subjects. These findings are similar to those of our study. Also, they found the Goodsall rule to be true in all cases, as internal openings were present 

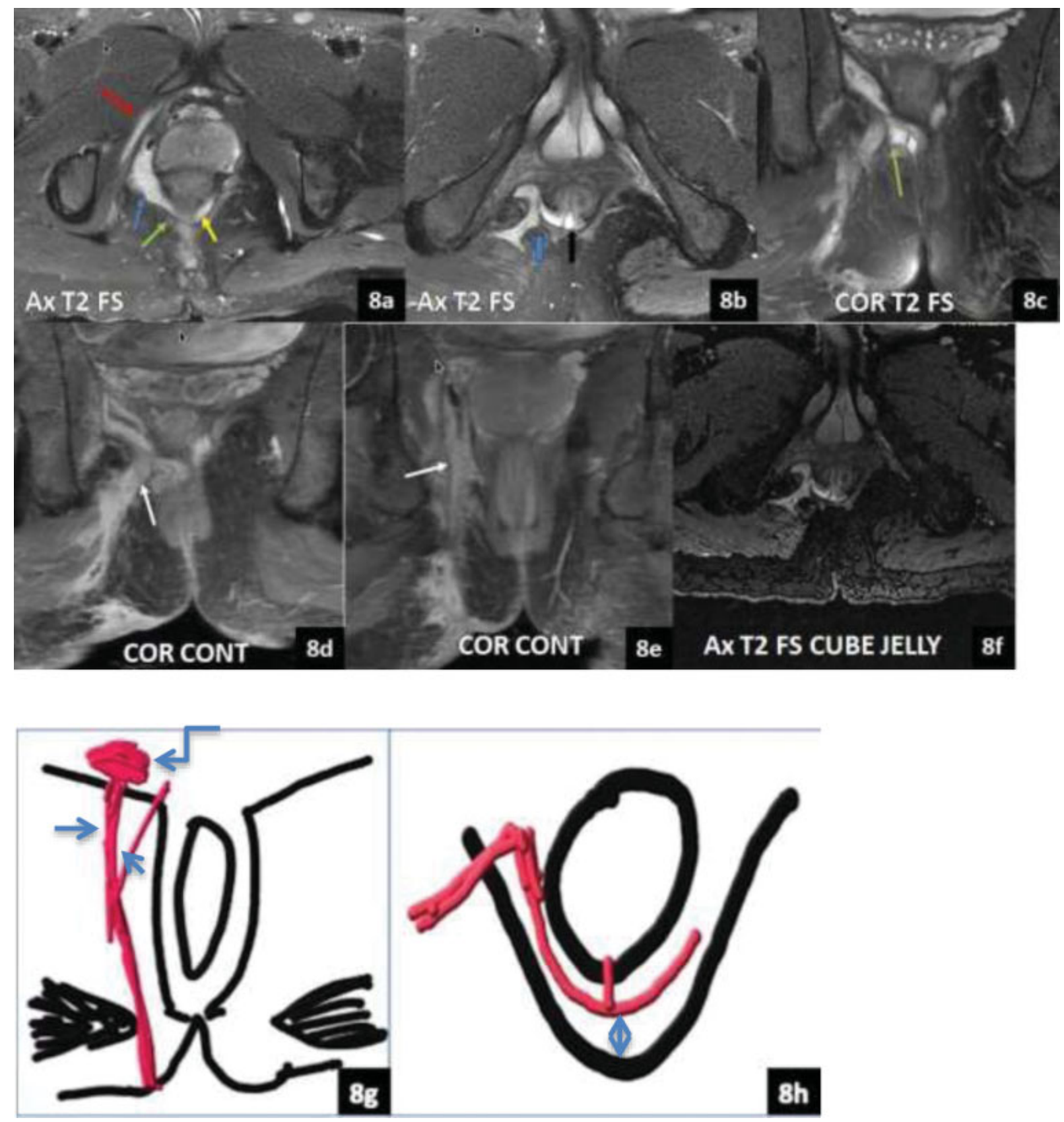

Fig. 8 SUPRALEVATOR FISTULA. (A) Axial T2 FS image showing collection (blue) deep into the levator muscle (green). Strip of hyperintensity in the right obturator internus muscle (red). Horseshoe tract also seen (yellow). (B) Axial T2 FS image showing fistula piercing the right levator ani muscle (blue), internal opening at 6 o'clock (black). (C) Cor T2 FS showing supralevator fistula piercing the levator ani. (D, E) Postcontrast coronal image showing peripheral enhancement of the abscess and two supralevator fistulas (white arrows). (F) AX T2 FS CUBE Jelly image showing the fistulous tract. Line diagrams $(\mathbf{G})$ Coronal and $(\mathbf{H})$ Axial images showing the two tracts piercing right levator ani (arrow), abscess deep to levator ani muscle (curved arrow) and horseshoe tract (double headed arrow).

Table 2 Agreement analysis between Plain and jelly MRI fistulography

\begin{tabular}{|l|l|l|l|l|}
\hline & PRIMARY TRACTS & SECONDARY TRACTS & HORSESHOE TRACT & INTRENAL OPENINGS \\
\hline Kappa statistic value & +1 & 0.90 & +1 & +1 \\
\hline$P$-value & - & 0.001 & - & - \\
\hline
\end{tabular}


Table 3 Agreement analysis between plain and contrast magnetic resonance imaging

\begin{tabular}{|l|l|l|l|l|}
\hline & PRIMARY TRACTS & SECONDARY TRACTS & HORSESHOE TRACT & INTERNAL OPENINGS \\
\hline Kappa statistic value & +1 & 0.89 & +1 & 0.25 \\
\hline$P$-value & - & 0.001 & - & 0.11 \\
\hline
\end{tabular}

Table 4 Agreement analysis between post jelly and contrast injection MRI fistulography

\begin{tabular}{|l|l|l|l|l|}
\hline & PRIMARY TRACTS & SECONDARY TRACTS & HORSESHOE TRACT & INTERNAL OPENINGS \\
\hline Kappa statistic value & +1 & 0.84 & 0.79 & 0.15 \\
\hline$P$-value & - & 0.02 & 0.03 & 0.25 \\
\hline
\end{tabular}

posteriorly in the midine. ${ }^{12}$ In our study, the Goodsall rule was followed in 26 subjects (86.6\%).

We also acquired postaqueous ultrasound jelly injection 3D CUBE T2 FS sequence in 29 subjects, as one patient had inactive tract at the time of study. Aggarwal et al. performed percutaneous instillation of aqueous jelly into the perianal fistulas in 64 subjects and the postjelly MR fistulography findings were compared with the surgical results, which showed a sensitivity of $97 \%$ and positive predictive value of $100 \%$ in comparison with peroperative findings. ${ }^{13}$ Waniczek et al. performed an MRI after injecting a few drops of gadolinium mixed with saline through the external fistulous opening in 14 subjects, and the surgical findings were consistent with radiological descriptions of 13 MRI fistulographies. ${ }^{9}$ Likewise, in our study, it was possible to diagnose the type of tract and compare it with the plain MRI findings in all 29 patients postjelly injection,. Between plain and post jelly injection MRI fistulographies, there was significant agreement in visualization of primary and secondary tracts, horseshoe tract, and internal openings (kappa statistic close to 1). Also, we performed postjelly 3D CUBE sequence, images could be reformatted in coronal plane, and the exact length of the tract could be measured.

A review of 33 fistulograms was performed; the authors found that abnormal communication existed between the perineal skin and the ano-rectum. The communicating tract was single in 19 cases, branched in 6 cases, compound in 3 cases, and there were 5 fistulous abscesses in their study. ${ }^{14}$ Our study also found single tracts to be the most common. In another study, both MRI and X-ray fistulography findings done in two separate groups of patients were compared with the surgical findings and found near 100\% sensitivity of MRI, while that of X-ray fistulography was very low. ${ }^{15}$ Sofic et al. compared the findings of X-Ray, computed tomography (CT), and MRI fistulography in 24 cases and found transphincteric fistulae to be the most common (29.16\%); intersphincteric (25\%), recto-vaginal (25\%), extrasphincteric (12.5\%), suprasphincteric (8.33\%), and abscess collections were seen in (16.6\%) patients. The authors found the accuracy of the classification of fistulas on X-ray fistulography to be $37.5 \%$, CT fistulography $50 \%$, and MRI $83.3 \%{ }^{16}$ In our study, diagnosis of the type of perianal fistulas and their complications could be made in all cases with an MRI, and the authors did not find the advantage of doing X-ray or CT fistulography.

Goodsall had described the relationship of the external cutaneous fistulous opening with that of the internal opening. The rule states that external openings anterior to the transverse anal line lead to direct radial fistulous tracks into the anal canal, while those posterior to the line track into the anal canal mid-line posteriorly. An exception to this rule is anterior fistulas lying more than $3 \mathrm{~cm}$ from the anus, as these usually have a curved track (similar to posterior fistulas) and open into the anal canal midline posteriorly. ${ }^{17}$ In our study, internal opening was not demonstrated on MRI and jelly MRI fistulogram in one patient. Twenty-three patients (76\%) had internal opening at 6 o'clock, and the Goodsall rule was applicable in 26 subjects (86.6\%). In 19 patients (73\%), the external opening was posterior to the transverse anal line, and the internal opening was seen at 6 o'clock; 4 patients had the external opening present anteriorly, but tract course posteriorly, with internal opening at 6 o'clock (15.3\%); 2 patients had external and internal openings at 12 o'clock, and one patient had external opening at 3 o'clock and internal opening at 2 o'clock (radial tracts), hence following the Goodsall rule in these 26 subjects. Cirocco et al. studied the accuracy of the Goodsall rule in 216 patients and found that $90 \%$ of 124 patients with an external opening posterior to the transverse anal line had anal fistulas tracking to the midline, while only $49 \%$ of the 92 patients with an external opening anterior to the transverse anal line had anal fistulas that tracked in the radial fashion predicted by Goodsall. ${ }^{18}$ Cirocco et al. suggested that the midline is the primary internal opening site of nearly all fistulas, with up to $95 \%$ accuracy. The authors concluded that the Goodsall rule was inaccurate for anterior off-midline external fistulous opening, which tend to curve to a midline internal opening rather than take a straight course. Hence, the midline rule had an increased positive predictive value for the location of the primary (internal) origin from $49 \%$ using the Goodsall rule to $71 \%$ using the midline rule. ${ }^{19}$ In our study, the majority of the patients followed both the Goodsall rule as well as the midline rule.

One major limitation of our study was that the surgical outcome was not taken into consideration, and the results should have been compared with the surgical findings. However, in our study, there was loss to follow-up of many 
patients, and a few patients did not opt for surgery. Also, the sample size was comparatively small; a larger sample size would have made the results more accurate.

\section{Conclusion}

Magnetic resonance imaging fistulography remains the investigation of choice for delineation of perianal fistulas due to its excellent soft-tissue resolution and demonstration of the external sphincter and pelvic floor. The course of the primary tract, presence of secondary tracts, inflammatory changes, and internal openings can be easily diagnosed on axial and coronal T2 and T2 fat sat sequences. The delineation of abscesses is better on postcontrast T1 TSE fat sat axial and coronal sequence; however, the decision of administering contrast can be taken while studying the plain scan findings if presence of abscess is suspected. Also, the accuracy of jelly MRI fistulography 3D axial T2 fat sat sequence was the same as that of the plain study, but it enabled reformation in other planes and maximum intensity projection (MIP) images for better demonstration of tracts as well as measuring their lengths. Hence, we suggest that instead of 2D axial T2 TSE fat sat, 3D T2 fat sat CUBE sequence should be incorporated in plain study. Jelly MRI fistulography is an optional study, which may be omitted as nearly all findings can be appreciated in the plain study itself. It is always better to provide line diagrams of the fistulous tracts at the end of the report to the operating surgeons for better understanding.

Conflict of Interests

The authors have no conflict of interests to declare.

\section{References}

1 Morris J, Spencer JA, Ambrose NS. MR imaging classification of perianal fistulas and its implications for patient management. Radiographics 2000;20(03):623-635, discussion 635-637

2 Gage KL, Deshmukh S, Macura KJ, Kamel IR, Zaheer A. MRI of perianal fistulas: bridging the radiological-surgical divide. Abdom Imaging 2013;38(05):1033-1042
3 Parks AG. Pathogenesis and Treatment of Fistula-in-ANO. BMJ 1961;81(01):463-469

4 Ziech M, Felt-Bersma R, Stoker J. Imaging of perianal fistulas. Clin Gastroenterol Hepatol 2009;7(10):1037-1045

5 Parks AG, Gordon PH, Hardcastle JD. A classification of fistula-inano. Br J Surg 1976;63(01):1-12

6 de Miguel Criado J, del Salto LG, Rivas PF, et al. MR imaging evaluation of perianal fistulas: spectrum of imaging features. Radiographics 2012;32(01):175-194

7 Al-Khawari HA, Gupta R, Sinan TS, Prakash B, Al-Amer A, AlBolushi $S$. Role of magnetic resonance imaging in the assessment of perianal fistulas. Med Princ Pract 2005;14(01):46-52

8 Khera PS, Badawi HA, Afifi AH. MRI in perianal fistulae. Indian J Radiol Imaging 2010;20(01):53-57

9 Waniczek D, Adamczyk T, Arendt J, Kluczewska E, Kozińska-Marek E. Usefulness assessment of preoperative MRI fistulography in patients with perianal fistulas. Pol J Radiol 2011;76(04):40-44

10 Daabis N, El Shafey R, Zakaria Y, Elkhadrawy O. Magnetic resonance imaging evaluation of perianal fistula. Egypt J Radiol Nucl Med 2013;44(04):705-711

11 Vo D, Phan C, Nguyen L, et al. The role of magnetic resonance imaging in the preoperative evaluation of anal fistulas. Sci Rep 9, 17947 (2019)https://doi.org/10.1038/s41598-019-54441-2

12 Joshi A, Bhuta M, Kulkarni S, Singh S, Modi TMR. IMAGING IN PERIANAL FISTULAS : A COMPARATIVE STUDY OF 25 PATIENTS. World Journal of Pharmaceutical And Medical Research 2016;2 (05):253-259

13 Aggarwal R, Soni BK, Kumar JU, George RA, Sivasankar R. MR fistulography with percutaneous instillation of aqueous jelly: A cost effective technique innovation. Indian J Radiol Imaging 2017; 27(02):161-166

14 Ani AN, Lagundoye SB. Radiological evaluation of anal fistulae: a prospective study of fistulograms. Clin Radiol 1979;30(01):21-24

15 Tripathi N, Chavan S, Bendre M, Sharma V. Comparative study of MRI fistulogram and X-ray fistulography with operative findings: in fistula in ano. Int Surg J 2019;6(05):1704

16 Sofic A, Beslic S, Sehovic N, Caluk J, Sofic D. MRI in evaluation of perianal fistulae. Radiol Oncol 2010;44(04):220-227

17 Goodsall DH, Miles EW. David Henry Goodsall 1843-1906. Dis Colon Rectum 1982;25(03):262-278

18 Cirocco WC, Reilly JC. Challenging the predictive accuracy of Goodsall's rule for anal fistulas. Dis Colon Rectum 1992;35(06):537-542

19 Cirocco WC, Reilly JC. It is time to retire Goodsall's Rule: the Midline Rule is a more accurate predictor of the true and natural course of anal fistulas. Tech Coloproctol 2020;24(04):317-321 